\section{Epidemiology of vertebral frac- tures in pediatric and adolescent patients}

\author{
Dominik Saul, Klaus Dresing \\ Department of Trauma, Orthopedics \\ and Reconstructive Surgery, Georg- \\ August-University of Goettingen, \\ Germany
}

\begin{abstract}
Spinal injuries in children and adolescents are rare injuries, but consequences for the growing skeleton can be devastating. Knowledge of accident causes, clinical symptoms and diagnostics should be part of every trauma department treating these patients. We retrospectively analyzed patients with radiographically proven vertebral fractures of the spine. After clinical examination and tentative diagnosis the fractures and injuries were proven with conventional X-ray, computed tomography (CT) scans or magnetic resonance imaging (MRI). The study included 890 fractures in 546 patients with an average age of $12.8 \pm 6.2$ (6.6-19.4) years. Females had an average age of $13.7 \pm 6.3$ (7.4-20.0) years, whereas males were on average 12.0 (6.0$18.0)$ years old. Fall from height (58\%) was the main cause of accident and the most common region of fracture was the thoracolumbar spine with a shift towards the thoracic spine the more fractures occurred. Merely $3.7 \%$ of all patients required operative treatment. If a vertebral fracture is found in children and adolescents, it is highly recommended to exclude synchronous additional spine fractures in other levels; prevention should concentrate on fall and traffic accidents.
\end{abstract}

\section{Introduction}

Fractures of the spine in children and adolescents are rare and cause $0.2 \%$ of all fractures in the pediatric population whereas structural lesions account for $0.6-3 \%$ of all spinal damages. ${ }^{1-3}$ This may be due to the fact that elasticity and mobility in infant spines is much higher than in adults and their pediatric body mass is lower. ${ }^{2}$ However, diagnosis remains challenging 4 and consequences for the growing skeleton such as spinal deformity, syringomyelia and scoliosis are devastating. ${ }^{4-7}$ Therefore, potential risk factors need to be investigated thoroughly.

In childhood, the vertebral end plate is a hard and thick cartilage tissue and annulus fibrosus is even supplied by vessels up to the age of 20 years. 8,9 The intervertebral disc has a strong texture since degeneration through oxidative stress and declining nutrition has not yet begun. ${ }^{10-13}$ These preconditions lead to a high resistance against sheerand compression forces. 14

Diagnosis of vertebral fractures in growing individuals still remains a challenging task since among others the late calcification of the epiphyseal plate makes radiologic diagnosis complicated. 15 The complex biomechanical composition of the pediatric spine requires special scientific approaches. For instance in a Japanese study a three-dimensional model-analysis of the pediatric lumbar spine has been created. 16 It indicated that anterior compartment stress in pediatric spine is extremely high, especially in the apophyseal bony ring due to increased stiffness in that region which could predetermine this area for fractures.

Injuries of the cervical spine are most common regarding the relatively high weight of the head, less muscular development and a greater elasticity of soft tissues. 14,17

The most frequent fracture types in pediatric spine are impression and compression fractures, ${ }^{18,19}$ whereas burst fractures with a complete rupture of stratum germinativum remain seldom. ${ }^{20,21}$

Since data of these unusual fracture injuries in children and adolescents, their reasons and treatment is rare, we analyzed 546 patients with proven injuries under sixteen years to show, which of the spinal bodies is mostly affected and if in general multiple injuries are more often than isolated. Another aim was to show how often the fractures needed to be operatively stabilized.

\section{Materials and Methods}

In a retrospective analysis in a German level-I-trauma center all patients with suspected injuries of the spine were examined using conventional X-ray, CT scans or MRI. The investigation period was from 1998 to 2014. For this analysis, emergency department records were reviewed and consecutive radiology studies performed. The databases used were the PACS, the radiology reports and the surgical report databank. For the operated patients, neurological outcome was assessed. Follow up evaluation was
Correspondence: Dominik Saul, Department of Trauma, Orthopedics and Reconstructive Surgery, Georg-August-University of Goettingen, Wilhelmsplatz 1, 37073 Göttingen, Germany.

Tel.: 01725844375 - Fax.: 0551-39-8981.

E-mail: DominikSaul@med.uni-goettingen.de

Key words: Pediatric spine trauma, vertebral fractures, adolescents, epidemiology, treatment.

Contributions: DS wrote the manuscript and did all the basic and advanced research, KD su-pervised the whole process.

Conflict of interest: the authors declare no potential conflict of interest.

Funding: none.

Received for publication: 18 April 2017.

Revision received: 4 March 2018.

Accepted for publication: 5 March 2018.

This work is licensed under a Creative Commons Attribution NonCommercial 4.0 License (CC BY-NC 4.0).

CC Copyright D.Saul and K. Dresing, 2018

Licensee PAGEPress, Italy

Pediatric Reports 2018; 10:7232

doi:10.4081/pr.2018.7232

conducted with X-ray and clinical examination, postoperatively, six weeks, three months, half a year and one year after the operation.

Inclusion criteria were: age 1 month to 15.9 years; radiographically demonstrated vertebral fractures; vertebral fractures; primary admission to the accident and emergency department (Clinic of trauma surgery and orthopedics, Department of Trauma and Reconstructive and Plastic Surgery of the University Medical Center Göttingen, UMG, Georg-August-University, Germany); period of admission: 01.01.1998 to 31.12 .2014 .

Exclusion criteria were: all patients with suspicion of spine trauma without verification in X-ray, CT or MRI; All patients older than 16.0 years.

\section{Statistics}

Statistical analyses were performed using GraphPad Prism version 5.04 for Windows, GraphPad Software, La Jolla California USA and unpaired, two-tailed ttest was used for comparative studies.

As part of the quality assurance project this review was checked by the local ethic committee (15/5/15An). 


\section{Results}

\section{Patient characteristics}

546 patients fulfilled the inclusion criteria. The population included 285 male $(52.2 \%)$ and 261 female patients $(47.8 \%)$. The patient group had a mean age of 12.8 \pm 6.2 [6.6-19.4] years; median 13.0. The examined females had an average age of $13.7 \pm 6.3$ [7.4-20.00] years, median 14.0 whereas the males were on average $12.0 \pm 6.0$ [6.0-18.0] years old, median 12.0.

The youngest observed infant was 1 month old. The course of the injury was followed in the individuals if required (maximum age in control was 29 years).

Out of this population 441 children $(80.8 \%)$ appeared to have vertebral fractures. The remaining 105 patients (19.2) had ligamentary lesions of luxations. Overall 890 fractures could be detected corresponding to 2 fractures per child on average. Radiologic methods included X-ray (546 times resulting in 3056 pictures), which was used more and more sparingly, CT (143 times) and MRI (54 times) (Figure 1A).

Generally, CT scans were carried out more regularly than MRI. However, the number of MRI analyses increased over the course of time (Figure 1A). Altogether 3056 X-rays were performed corresponding to 5.6 pictures per child. $11 \mathrm{CT}$ scans and 5 MRIs were taken pre-operatively.

\section{Fracture distribution pattern}

The distribution of all fractures was determined and showed a peak in the thoracolumbar area (L1 and T12; Figure 1B).

Among 890 fractures in 546 patients, 80 fractures were observed in the cervical region, 505 in the thoracic region and 277 in the lumbar spine.

Patients with one vertebral fracture had a mean age of 12.69 \pm 6.20 [6.49-18.89], median 12.0 years, patients with more than one fracture had a mean age of $13.3 \pm 6.29$ [6.99-19.57], median 14.0 years, with a slight tendency to younger patients having less fractures $(\mathrm{P}=0.1998)$.

The number of fractures per patient has been determined. Less than half of all fractures occurred only as single fracture (206) and most children were found to have more than one fracture (Figure 1C) with a multiple fracture rate of $53.19 \%$.

206 patients had one fracture $(46.81 \%)$ with a lumbar peak, 235 had more than one fracture, while 129 (29.32\%) had two fractures with a shift to the thoracic spine, 49 $(11.14 \%)$ three fractures (thoracic spine in most cases) and $57(12.73 \%)$ more than three fractures with a peak in the thoracic region (Figure 1C,D).
Patients with just one fractured spinal body had a lumbal injury in most cases. Furthermore, we took a closer look on the number of lesions in correlation to the vertebral location and found a shift towards the thoracic spine (Figure 1D).

Patients with cervical lesions had a mean age of 12.0 years, patients with thoracic fractures an age of 13.38 years, patients with lumbar fractures an age of 12.86 years (Figure 2A).

\section{Causes of injury}

There were three types of accidents resulting in pediatric spine fractures: fall, traffic injury and sports (Figure 2B). Fall was the most common cause with 315 patients $(57.8 \%$, mean age: 13.06 years, thoracolumbar peak, Figure 2D), followed by 180 traffic accidents $(33.03 \%$, mean age: 12.54 years, peak in the thoracolumbar area, Figure 2C) and 50 sporting accidents (9.17\%, mean age: 12.42 years, thoracic peak, Figure 2E). Age could not be correlated to the cause of accident (traffic accident vs. fall $\mathrm{P}=0.37$; fall $v$ s. sports $\mathrm{P}=0.66$; traffic accident $v s$. sports $\mathrm{P}=0.94$ ).

Comparing the reasons of injury with the level of lesion, no significant differences can be detected.

\section{Age}

Age-related injuries were investigated by dividing the cohort into four age-groups (Figure 3A).

In patients younger than five years, a
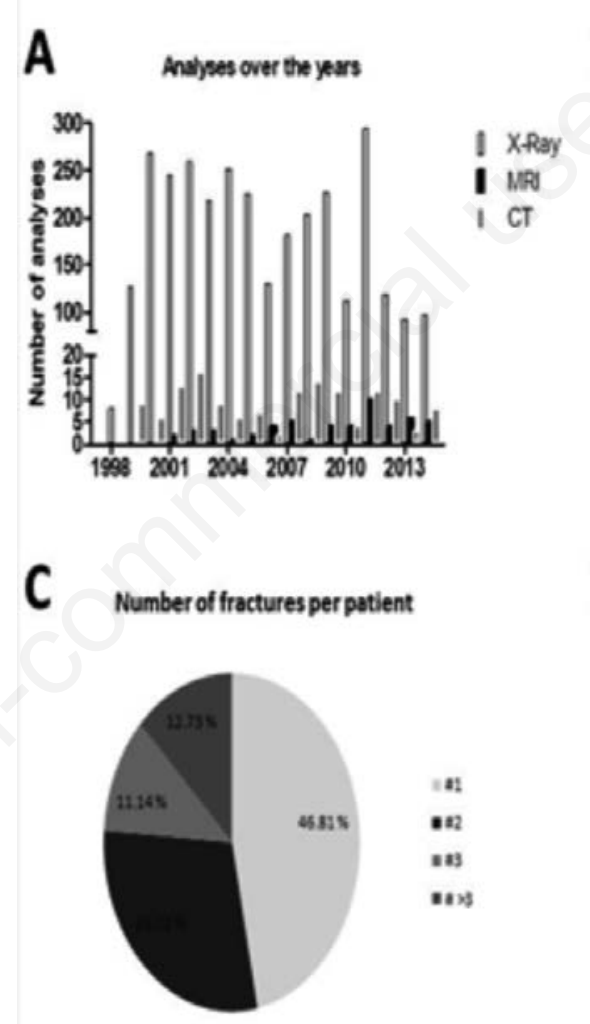

B

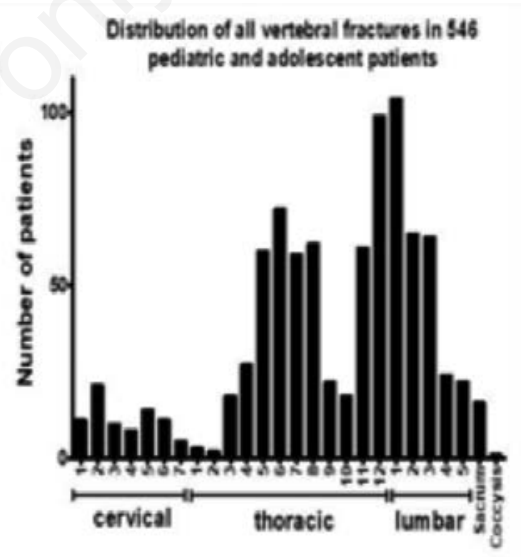

D

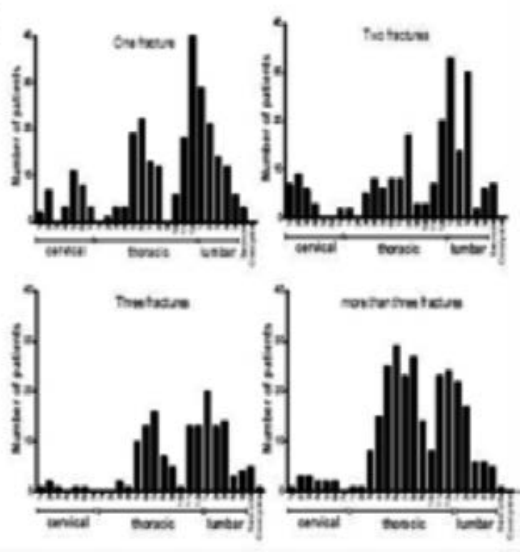

Figure 1. The number of X-rays, CT scans and MRIs performed from 1998 to 2014 (A). The use of di-agnostic tools reveals a slight increase in the number of MRI scans in the past several years, whereas X-rays were used more and more sparingly. The distribution of vertebral fractures in all 546 pediatric and adolescent patients (B). The localization of fractures was observed, and the distribution revealed a thoracolumbar peak. Number of fractures per patient $(C)$. The number of fractures per patient was determined. Less than half of all fractures occurred as single fractures (206), and most children exhibited more than one fracture (129 had two fractures, 49 had three fractures, and 56 had more than three fractures). The Distribution of fractures (D) in 206 patients with one fracture exhibits a lumbar peak, while the 129 patients with two fractures show a shift to the thoracic spine. In the three fractures group of 49 patients, the thoracic spine-shift is continued while in 57 patients with more than three fractures, the peak in the thoracic region becomes greater 
peak at T8 and a broad lumbar peak can be detected $(n=90)$ followed by a thoracolumbar peak in the 5-10-year old children $(\mathrm{n}=161)$. In young teenagers, the lumbar region becomes more and more affected $(n=209)$ when finally in older teenagers from 15 years on the lumbar region is most affected $(n=304)$.

\section{Operative treatment}

In 20 patients the indication for operative treatment was given $(3.7 \%)$, and most commonly performed in the lumbar spine (Figure 3B). 13 of these suffered from neurological deficits. Indication for operative intervention were these neurological deficits, Denis' 3-column injuries or unstable fractures. ${ }^{22} 12$ received a dorsal spondylodesis. The average age of operated children was 13.7 years. After one year, all of the operated patients had consolidated fractures. No new neurological deficit was reported after the operation. Except one stress incontinence, no neurological abnormality was reported after one year.

None of the conservatively treated patients needed to be operated secondarily because of missing fracture healing.

Comparing the three major types of accident causes, no significant differences can be found in the resulting number of fractures whereas in traffic accidents $(n=145)$, single fractures represent less than half of all fractures and single fractures represent more than $60 \%$ of all fractures in sporting accidents ( $n=10$, Figure $3 C)$.

Furthermore looking at the number of fractures, most of single $(n=201)$, double $(n=119)$ and multiple fractures $(n=55)$ are caused by fall due to the fact that fall was totally the most frequent reason of injury (Figure 3D).

\section{Discussion}

Vertebral fractures in pediatric and adolescent patients remain a rare injury in German hospitals. Since evidence is limited in clearing spine in pediatric patients, ${ }^{23}$ clinical approach remains difficult and consequences of injuries can be devastating.

\section{Diagnostics}

With our diagnostic pathway, the number of used diagnostic tools shows a slight increase in MRI scans in the last years whereas X-rays were used more and more economically (Figure 1A). CT scans were carried out in a similar frequency over the years with a slight decrease in the last years. Considering the radiation exposure, the increased utilization of computed tomogra- phy as described by Adelgais et al. in a 5148 patient study, ${ }^{24}$ or by Mannix et al. in a 929,626 patient study 25 could not be confirmed in our investigation. Due to the $100 \%$ sensitivity of MRI contrary to $23 \%$ in computed tomography, ${ }^{26}$ MRI was used regularly with $0.1 \mathrm{MRI} /$ child on average (0.3 CT/child on average).

One reason for our restrained usage of CT in the last years could be the 24/7 availability of MRI. The radiation hygiene considering for instance the theoretical risk of thyroid cancer in pediatric patients is another reason for modest usage of CT. 27

We have not observed children with real SCIWORA-Syndrome. The first 1982 described SCIWORA (spinal cord injury without radiographic abnormality), 28 which prevalence is seen controversial in the literature with a broad range from 5 to $67 \%, 29$ 3.3 to $32 \%, 30$ or 6 to $19 \%, 31$ with its frequency dependent upon the utilization of $\mathrm{MR},{ }^{31}$ was reported in 16 cases, corresponding to $2.9 \%$ in our study if the old defini-
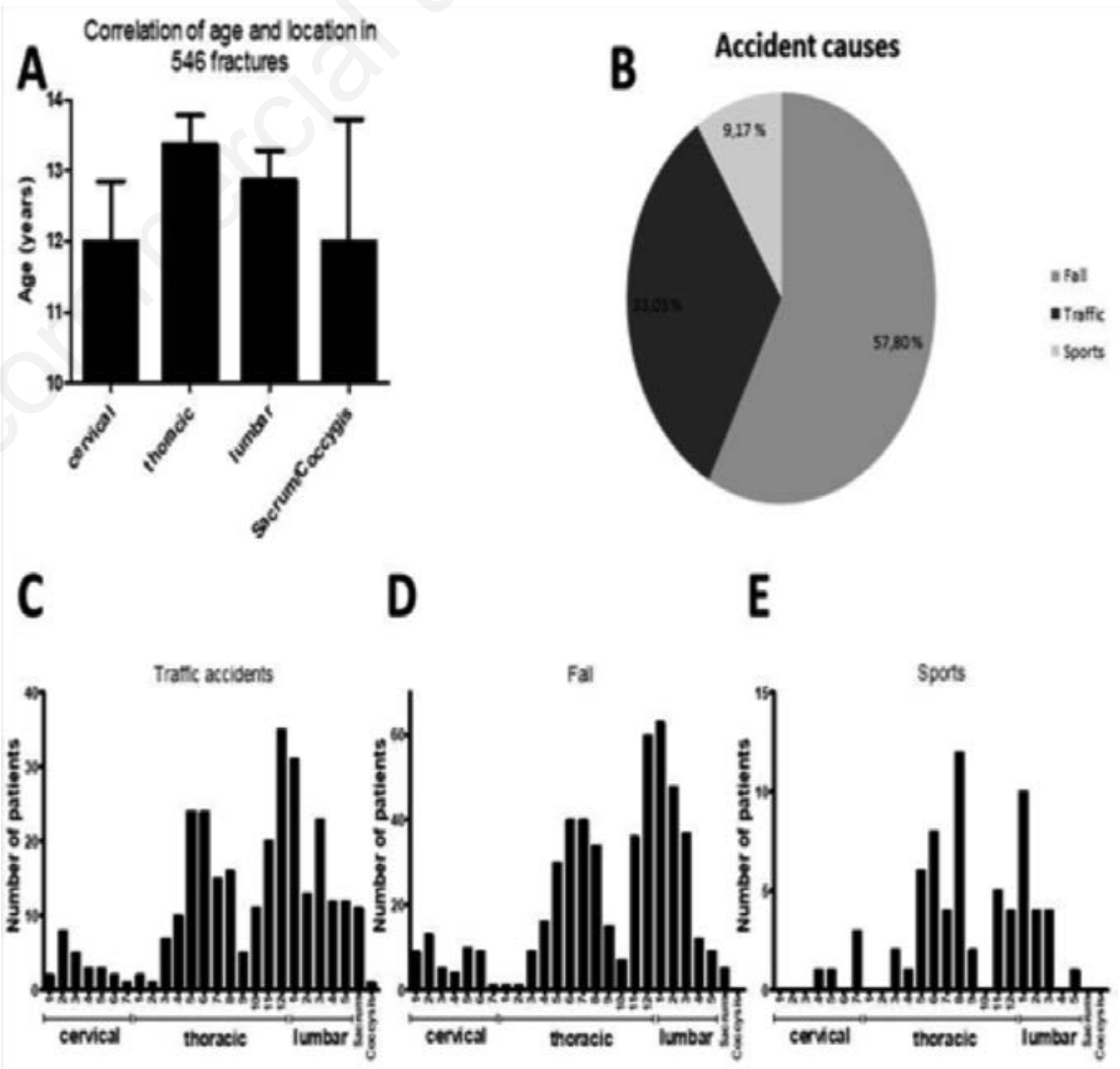

Figure 2. Correlation of age and location in 546 fractures (A). Younger patients had a tendency to injure the cervical spine. Accident causes (B). Falls were the most common reason for injury followed by traffic and sporting accidents. Localization of 297 fractures in traffic accidents (C) with a peak in the thoracolumbar area, after fall with 514 fractures and a peak in the thoracolumbar area as well (D) and during sports activities with 68 fractures $(\mathrm{E})$ and a thoracic peak.

tion is used. If MRI-detected pathologies would be classified as exclusion criteria for real SCIWORA or SCIWNA (spinal cord injury without neuroimaging abnormality), ${ }^{30,31}$ no real case could be reported.

There is no consent about the vertebral fracture distribution and location in pediatric and adolescent patients. While some show a peak in the thoracolumbar verte,32-34 others report T4 and L2 as main depending upon whether single or multiple fractures were observed (Table 1). ${ }^{38-48}$

\section{Location of injury - single fractures}

Looking closer at the anatomical distribution, $\mathrm{Hu}$ et al. ${ }^{33}$ found a distribution of cervical $(19.3 \%)$, thoracic $(30 \%)$ and lumbar/sacrococcygeal injuries $(42.5 \%)$ similar to our observations in a complete population.

Since we just examined pediatric fractures, the results of Siminoski et al. ${ }^{38}$ which included 94 patients are much better com-

[Pediatric Reports 2018; 10:7232]

[page 19] 
parable to our findings with a first peak at T7/T8 and a second peak at T12/L138 which could also be found by Dickman et al. (T11L2) ${ }^{39}$ and Reddy et al. 40 These reproduce our findings almost perfectly (Figure 1B, Table 1).

Considering all fractures, $27 \%$ were found at $\mathrm{T} 7 / \mathrm{T} 8$ and $17 \%$ at $\mathrm{T} 12 / \mathrm{L} 1.38$ In our study there was a greater fraction in the thoracolumbar area which could root in the older cohort of this analysis, a fact supported by Figure $3 \mathrm{~A}$ and $\mathrm{B}$ that shows patients less than 5 and between 5 and 10 years and fit to this distribution much better.

\section{Location of injury - multiple frac- tures}

The average age of children has been correlated to the number of fractures. Older patients tend to have more than one lesion. This tendency can also be found in an investigation of Rush et al.,37 where multiple fractures were found more frequently in the 13 to 19 -years old group than in the younger 4 to 12-years old group. The percentage of multiple fractures in our study was $53.2 \%$ which is comparable to the literature. $37,49-51$

These data underline that if a vertebral fracture in children is found, it is strictly indicated to seek for a second injury since multiple fractures are observed more frequently than in adults. ${ }^{50-52}$

The distribution of a single spinal fracture per patient shows a lumbar peak, whereas the distribution of two fractures shows a shift to the thoracic part, which is continued in the three-fracture-distribution, followed by a peak in the thoracic region if more than three fractures occur (Figure 1D). Taken together, the more damaged a spine is, the more likely is an injury of the thoracic spine. The shift to the thoracic spine in multiple fractures could also be seen in a large Chinese study. 48

\section{Age}

Age correlated to spinal fracture shows a tendency of younger patients to be injured in the cervical spine, correlating to the series of Osenbach et al. in which a higher fraction of cervical injuries could be measured in the younger group (79\%) compared to the older group (54\%) and lesions in the cervical spine were twice as often in younger children. ${ }^{53}$ This was similarly shown in a study with 406 patients under 14 years, in which the cervical region was mostly affected, but there were no differences between the age groups. ${ }^{42}$

Our youngest patient group $(<5$ years, Figure 3A) shows a thoracic fracture peak at T8 (Siminoski: peak at T7/T8, 28\%) ${ }^{38}$ and a broad peak at T12-L3 (Siminoski: broad peak across $\mathrm{T} 11$ to $\mathrm{L} 2,40.38$

We could also demonstrate this tendency to cervical injuries in younger patients which is analogous to previous studies. $5,54,55$ This can be explained by the relatively high weight of the head as explained above.

Analyzing children from 5-10 and 1015 years (Figure 3A), the thoracolumbar region is mostly affected in T5-7 (Siminoski: 45\%) and T12-L2 (Siminoski: $21 \%$ ), which can also be seen in the distribution by Siminoski. 38

The lumbar region is most frequently affected in older teenagers (Figure 3A) as demonstrated by Sayama et al. in 2014,56 and similar to grown-up patients. 48
Regarding the four age-related groups, cervical fractures remain a very rare injury. The shift towards the lumbar region becomes stronger with every year the pediatric patient gets older (Figure 3A), which can be similarly seen by Siminoski et al. 38 and Reddy et al. ${ }^{40}$

We summarize that the more fractures were found in children, the more likely the thoracolumbar spine was injured.

\section{Causes of injury}

Frequency of accident causes shows that fall is the most common reason of injury followed by traffic and sporting accidents, while Leucht et al. $(\mathrm{n}=562), 57$ also

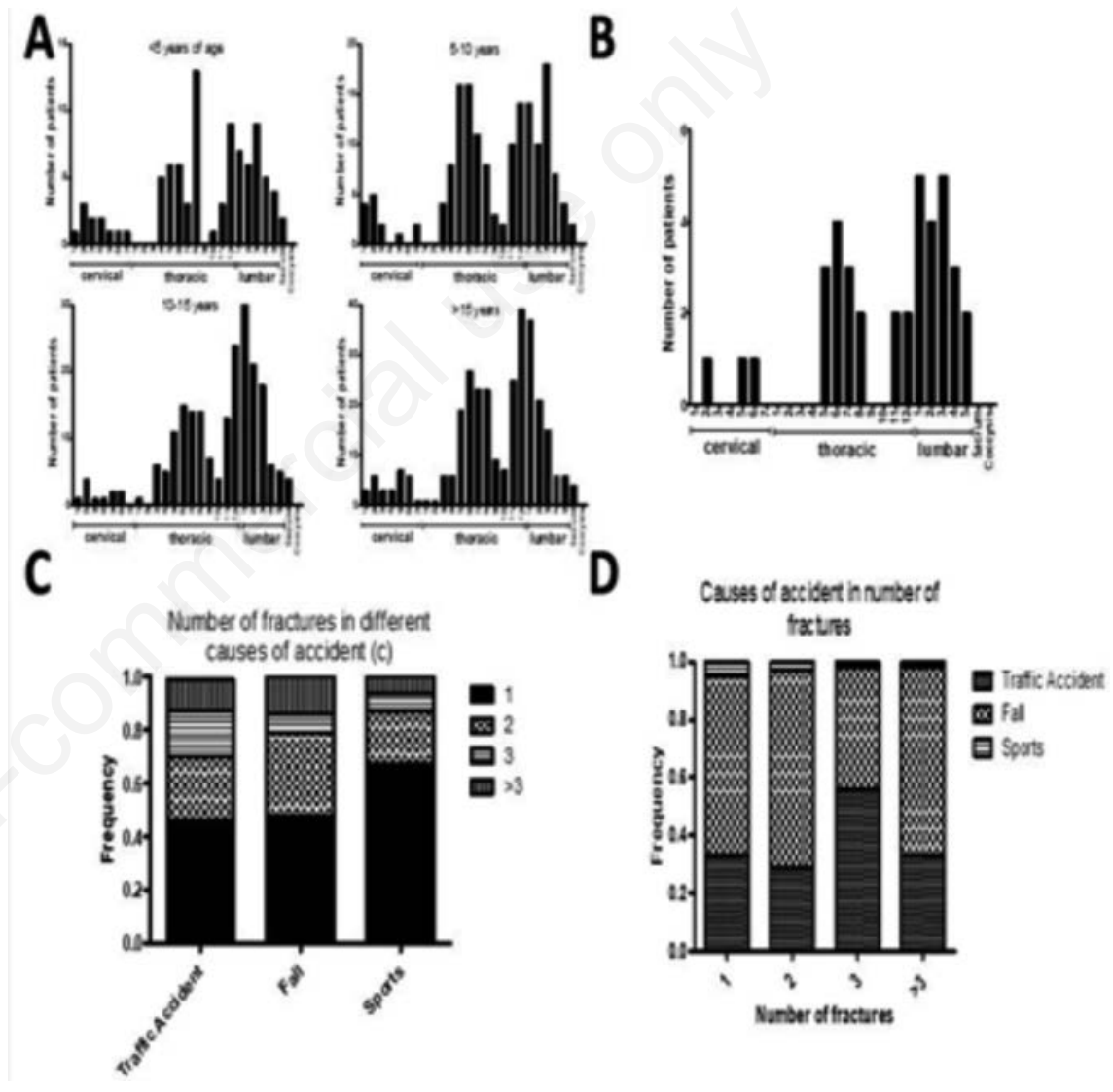

Figure 3. Localization of fractures in different ages (A). Localization of 90 fractures in children $<5$ years of age. A peak in T8 next to the lumbar peak can be detected in the youngest patients Between 5 and 10 years of age, the thoracolumbar region is mostly affected (161 fractures). The lumbar region is mostly affected in 209 teenage fractures between 10 and 15 years. In adolescents from 15 years on, the lumbar region remains the most affected region in 304 fractures. Thirty-eight operated fractures correlated with the location of vertebral fractures (B). Surgery was most commonly performed in the lumbar spine followed by the thoracic region. Injuries in the cervical spine rarely underwent surgery. Number of frac-tures in different causes of accident $(C)$. In traffic accidents, single fractures represent less than half of all fractures, whereas single fractures represent more than $60 \%$ of all fractures in sporting accidents (Traffic accidents: 145, Falls: 260, Sports: 10). No statistically significant differences were noted among the causes of accident. Causes of accident in number of fractures (D). Single fractures are mostly caused by falls followed by traffic accidents. This distribution was also noted for double and multiple fractures (single fractures: 201, double fractures: 119, triple fractures: 45 , multiple fractures: 55$)$. 
see fall $(39 \%)$ followed by traffic accidents $(26.5 \%)$ as main causes. Nau et al. observed more than half of all injury causes in traffic and by fall. ${ }^{58} \mathrm{~A}$ probable reason could be the greater city in which the study of Nau et al took place (Frankfurt/Main, Germany). Osenbach et al. ${ }^{53}$ also see vehicular accidents followed by falls as the main courses of accident and also represent a greater city (Iowa City).

Summarizing the reasons of injury, fall and traffic accidents followed by sporting accidents could be reported the most dangerous causes in our patients as also found in several other studies (Table 2). $35,36,42,48,53,58-64$

Localization of fracture in traffic accidents shows a peak in the thoracolumbar area (Figure 2C), which can be confirmed by the large study of Wang et al., where $41.57 \%$ of all fractures could be detected between $\mathrm{T} 11$ and L2.46

In the same study, the peak in the thoracic and lumbar area in fractures after fall which we could show (Figure 2D) can be confirmed since 58/62.5\% (distributed in less or more than 2 meters) of all fractures arose between T11 and L2.48

Concerning sport accidents, Wang et al. ${ }^{48}$ considered $61 \%$ of all fractures between $\mathrm{T} 11$ and $\mathrm{T} 2$ with $18 \%$ between $\mathrm{T} 1$ and $\mathrm{T} 10$ and $19 \%$ between L3 and L5, which seems to be more caudal than our distribution (Figure 2E). A possible reason could be the low number of sport accidents in this study $(\mathrm{n}=15)$.

\section{Treatment}

In most cases, conservative treatment of the fracture was indicated $(96.3 \%)$ as shown by several other studies $(76 \% 53 \%) .45,65$ Thus conservative treatment still has its relevance in pediatric spinal trauma since the broken vertebra has a high stability. ${ }^{66}$ In our study, indication for operative stabilization was very strict according to Jarvers et al. and the great remodeling potential of juvenile spine. 67,68 Neurological deficit or unstable fractures lead to surgery as reviewed by Sayama et al.56 If necessary, surgery most commonly took place in lumbar spine, followed by the thoracic region (Figure 3B). Cervical spine was rarely operated, only two times in our patients. This can also be seen in a study by Dogan et al. 65 where the thoracic and lumbar region was most commonly operated. Results after the operation were good, comparable to a review by $\mathrm{Basu}^{7}$ and a study by Suttor et al. ${ }^{69}$ These results suggest that younger patients are preferably treated without operation. Most operable lesions can be found in the thoracolumbar area.

Neurologic outcomes in younger chil-

Table 1. Literature localization of injury.

\begin{tabular}{|c|c|c|c|c|}
\hline Author [ref.] & No. & Cervical, \% & Thoracic, \% & Lumbar, \% \\
\hline Carreon et al. [41] & 36 & 36 & 34 & 29 \\
\hline Cirak et al. [42] & 145 & 61.4 & 15.9 & 22.8 \\
\hline Dickman et al. [39] & 104 & 44 & 48 & 8 \\
\hline Hofbauer et al. [43] & 28 & 0-9 years: upper spine & & Adolescents: lumbar region \\
\hline Hu et al. [33] & 2063 & 19.3 & 30 & $42.5 \%$ \\
\hline Liu et al. [44] & 82,720 & $<10$ years: 78.69 & & \\
\hline Özkan et al. [45] & 75 & 56 & & \\
\hline Parente et al. [46] & 130 & & 63 & \\
\hline Reddy et al. [40] & 164 & 8.9 & 28.7 & 23.2 \\
\hline Sawyer et al. [47] & 4483 & 16 & 39 & 29 \\
\hline Siminoski et al. [38] & 221 & & 72 & 28 \\
\hline Wang et al. [48] & 3142 & 20.5 & 30.5 & 49.0 \\
\hline
\end{tabular}

Table 2. Literature causes of spine injury.

\begin{tabular}{lcccc}
\hline Author [ref.] & No. & Traffic, \% & Fall, \% & Sports, \% \\
Álvarez-Pérez \& López-Llano [69] & 72 & 52.1 & - & - \\
Cirak et al. [42] & 406 & 29 & 26 & 20 \\
\hline Leonard et al. [60] & 540 & $37-56$ & - & - \\
Mortazavi et al. [61] & 103 & $48-61$ & - & $20-38$ \\
\hline Murphy et al. [62] & 51 & 53 & - & 14 \\
Nau et al. [58] & 49 & 37 & 16 & 12 \\
\hline Osenbach et al. [53] & 179 & 56 & 17 & 13 \\
Parente et al. [46] & 71 & 23.3 & - & - \\
\hline Patel et al. [63] & 1098 & 61 & $11-18$ & $3-20$ \\
Schottler et al. [64] & 159 & 49 & 6 & 1 \\
\hline Wang et al. [48] & 3142 & 20.9 & 58.9 & 5.5 \\
\hline
\end{tabular}

dren with cervical spinal fracture were reported poor, some studies account just $78 \%$ normal neurologic status after discharge from hospital, which we cannot confirm. 60 Other authors report good or excellent neurological function after thoracic and lumbar fractures. ${ }^{56,70}$ In an investigation by Erfani et al., out of 102 pediatric patients, in which 20 patients underwent surgery, all patients achieved full functional independence afterwards. ${ }^{71}$ In a great retrospective analysis by Williams et al., new postoperative neurological deficits were with $0.9 \%$ a rare complication after traumatic spinal fractures, ${ }^{72}$ matching well with our results.

Regarding multiple fractures and its special diagnostic difficulty, ${ }^{73}$ a high-energy trauma, e.g. traffic accidents ${ }^{74}$ and highenergy falls ${ }^{57}$ could be assumed. Comparing the three major types of accident causes, no significant differences can be found in the resulting number of fractures which could also be seen by Reddy et al. ${ }^{40}$ and Cirak et al. ${ }^{46}$ Furthermore looking at the number of fractures, most of single, double and multiple fractures are caused by fall attributable to the fact that fall was totally the most frequent reason of injury. Though no distinct cause of multilevel lesions could be reported in our study and a research by Mahan et al., ${ }^{75}$ maybe every higher energy is dissipated in the smaller body of pediatric patients leading to multiple fractures. ${ }^{41}$ Our data underline that cervical injuries occur more likely in younger patients as reported in other studies. 1,2,54,76,77 Multi-segmented injuries are more typical to the older children (Figure 3A). ${ }^{2}$ Nonetheless, a high estimated number of unknown cases remains as shown in a Swiss necropsy-study from 1974 where just one out of 12 spinal injuries could be reported radiologically and in all lesions the growth zone of the cartilaginous end-plate was fractured. ${ }^{78}$

\section{Conclusions}

We could demonstrate that multi-segment injuries are more frequent than single injuries and that the major cause of vertebral injuries are falls. These data demonstrate that vertebral fractures in children are 
usually multiple and should lead to broad diagnostic coverage. Prevention should especially conceal falls and traffic accidents. Lesions for operative fixation are rare due to the great elasticity of pediatric spine, but if surgery is required, it takes place generally in the thoracolumbar area.

\section{References}

1. Weinberg A, Tscherne H, Henkel R. Tscherne Unfallchirurgie: Untere Extremität, Wirbelsäule, ... des kindlichen Skelettes (German Edition). Dordrecht: Springer; 2006.

2. Stulík J, Pesl T, Kryl J, et al. Poranení pátere u detí a adolescentů. Acta Chir Orthop Traumatol Cech 2006;73:31320

3. Reynolds R. Pediatric spinal injury. Curr Opin Pediatr 2000;12:67-71.

4. Eubanks JD, Gilmore A, Bess S, Cooperman DR. Clearing the pediatric cervical spine following injury. $\mathrm{J}$ Am Acad Orthop Surg 2006;14:552-64.

5. Parent S, Mac-Thiong JM, RoyBeaudry M, et al. Spinal cord injury in the pediatric population: a systematic review of the literature. J Neurotrauma 2011;28:1515-24.

6. Tat ST, Mejia MJ, Freishtat RJ. Imaging, clearance, and controversies in pediatric cervical spine trauma. Pediatr Emerg Care 2014;30:911.

7. Basu S. Spinal injuries in children. Front Neurol 2012;3:96.

8. Moore RJ. The vertebral end-plate: what do we know? Eur Spine J 2000;9:92-6.

9. Rudert M, Tillmann B. Lymph and blood supply of the human intervertebral disc. Cadaver study of correlations to discitis. Acta Orthop Scand 1993;64:37-40.

10. Buckwalter JA. Aging and degeneration of the human intervertebral disc. Spine. 1995;20:1307-14.

11. Hou G, Lu H, Chen M, et al. Oxidative stress participates in age-related changes in rat lumbar intervertebral discs. Arch Gerontol Geriatr 2014:59:665-9.

12. Roberts S, Johnson WE. Analysis of aging and degeneration of the human intervertebral disc. Spine 1999;24:5001.

13. Shapiro IM, Risbud MV, eds. The Intervertebral Disc: Molecular and Structural Studies of the Disc in Health and Disease. Vienna, s.1.: Springer Vienna; 2014

14. Nuckley DJ, Ching RP. Developmental biomechanics of the cervical spine: Tension and compression. J Biomech 2006;39:3045-54.

15. Taylor JAM, Resnick D. Skeletal imaging: Atlas of the spine and extremities. 2nd ed. Philadelphia: Elsevier Saunders; 2010.

16. Sairyo K, Goel VK, Masuda A, et al. Three-dimensional finite element analysis of the pediatric lumbar spine. Part I: pathomechanism of apophyseal bony ring fracture. Eur Spine J 2006;15:923-9.

17. Stulík J, Nesnídal P, Kryl J, et al. Nestabilní poranění horní krční páteře u dětí a adolescentů. Acta Chir Orthop Traumatol Cech 2013;80:106-13.

18. Junewick JJ, Borders HL, Davis AT. Pediatric thoracic spine injuries: a single-institution experience. AJR Am J Roentgenol 2014;203:649-55.

19. Schrödel M, Hertlein H. Halswirbelsäulenverletzungen im Kindes- und Jugendalter. Unfallchirurg 2013;116:1054.

20. Vander Have KL, Caird MS, Gross S, et al. Burst fractures of the thoracic and lumbar spine in children and adolescents. J Pediatr Orthop 2009;29:713-9.

21. Lalonde F, Letts M, Yang JP, Thomas K. An analysis of burst fractures of the spine in adolescents. Am J Orthop 2001;30:115-20.

22. Denis F. The Three Column Spine and Its Significance in the Classification of Acute Thoracolumbar Spinal Injuries. Spine 1983;8:817-31.

23. Slack SE, Clancy MJ. Clearing the cervical spine of paediatric trauma patients. Emerg Med J 2004;21:189-93.

24. Adelgais KM, Browne L, Holsti M, et al. Cervical spine computed tomography utilization in pediatric trauma patients. J Pediatr Surg 2014;49:333-7.

25. Mannix R, Nigrovic LE, Schutzman $\mathrm{SA}$, et al. Factors associated with the use of cervical spine computed tomography imaging in pediatric trauma patients. Acad Emerg Med 2011;18:905-11.

26. Henry M, Riesenburger RI, Kryzanski $\mathrm{J}$, et al. A retrospective comparison of $\mathrm{CT}$ and MRI in detecting pediatric cervical spine injury. Childs Nerv Syst 2013;29:1333-8.

27. Muchow RD, Egan KR, Peppler WW, Anderson PA. Theoretical increase of thyroid cancer induction from cervical spine multidetector computed tomography in pediatric trauma patients. J Trauma Acute Care Surg 2012;72:4039.

28. Pang D, Wilberger JE. Spinal cord injury without radiographic abnormali- ties in children. J Neurosurg 1982;57:114-29.

29. Pang D. Spinal cord injury without radiographic abnormality in children, 2 decades later. Neurosurgery 2004;55:1325.

30. Yucesoy K, Yuksel KZ. SCIWORA in MRI era. Clin Neurol Neurosurg 2008;110:429-33.

31. Szwedowski D, Walecki J. Spinal Cord Injury without Radiographic Abnormality (SCIWORA) - Clinical and Radiological Aspects. Pol J Radiol 2014;79:461-4.

32. Jansson KA, Blomqvist P, Svedmark $P$, et al. Thoracolumbar vertebral fractures in Sweden: an analysis of 13,496 patients admitted to hospital. Eur J Epidemiol. 2010;25:431-7

33. $\mathrm{Hu} \mathrm{R}$, Mustard CA, Burns C. Epidemiology of incident spinal fracture in a complete population. Spine 1996;21:492-9.

34. Rajasekaran S, Kanna RM, Shetty AP. Management of thoracolumbar spine trauma: An overview. Indian J Orthop 2015;49:72-82.

35. Hegenbarth R, Ebel KD. Roentgen findings in fractures of the vertebral column in childhood Examination of 35 patients and its results. Pediatr Radiol 1976;5:34-9.

36. Horal J, Nachemson A, Scheller S. Clinical and radiological long term follow-up of ventebral fractures in children. Acta Orthop Scand 1972;43:491503.

37. Rush JK, Kelly DM, Astur N, et al. Associated injuries in children and adolescents with spinal trauma. J Pediatr Orthop 2013;33:393-7.

38. Siminoski K, Lee $\mathrm{KC}$, Jen $\mathrm{H}$, et al. Anatomical distribution of vertebral fractures: comparison of pediatric and adult spines. Osteoporos Int 2012;23:1999-2008.

39. Dickman CA, Rekate HL, Sonntag VK, Zabramski JM. Pediatric spinal trauma: vertebral column and spinal cord injuries in children. Pediatr Neurosci 1989; $15: 237$.

40. Reddy SP, Junewick JJ, Backstrom JW. Distribution of spinal fractures in children: does age, mechanism of injury, or gender play a significant role? Pediatr Radiol 2003;33:776-81.

41. Carreon LY, Glassman SD, Campbell MJ. Pediatric spine fractures: a review of 137 hospital admissions. J Spinal Disord Tech 2004; 17:477-82.

42. Cirak B, Ziegfeld S, Knight VM, et al. Spinal injuries in children. J Pediatr Surg 2004;39:607-12.

43. Hofbauer M, Jaindl M, Höchtl LL, et al. 
Spine injuries in polytraumatized pediatric patients: characteristics and experience from a Level I trauma center over two decades. J Trauma Acute Care Surg 2012;73:156-61.

44. Liu P, Yao Y, Liu MY, et al. Spinal trauma in mainland China from 2001 to 2007: an epidemiological study based on a nationwide database. Spine 2012;37:1310-5.

45. Özkan N, Wrede K, Ardeshiri A, et al. Management of traumatic spinal injuries in children and young adults. Childs Nerv Syst 2015;31:1139-48.

46. Parente A, Navascués JA, Hernández E, et al. Lesiones raquimedulares en la infancia. Cir Pediatr 2005;18:132-5.

47. Sawyer JR, Bernard MS, Schroeder RJ, et al. Trends in all-terrain vehicle-related spinal injuries in children and adolescents. J Pediatr Orthop 2011;31:6237.

48. Wang H, Zhang Y, Xiang Q, et al. Epidemiology of traumatic spinal fractures: experience from medical university-affiliated hospitals in Chongqing, China, 2001-2010. J Neurosurg Spine 2012;17:459-68.

49. Leonard M, Sproule J, McCormack D. Paediatric spinal trauma and associated injuries. Injury 2007;38:188-93.

50. Wittenberg RH, Hargus S, Steffen R, et al. Noncontiguous unstable spine fractures. Spine 2002;27:254-7.

51. Wang H, Xiang Q, Li C, Zhou Y. Multiple-level noncontiguous spinal fractures: difference between the young and the elderly. J Spinal Disord Tech 2013;26:6.

52. Vaccaro AR, An HS, Lin S, et al. Noncontiguous injuries of the spine. J Spinal Disord 1992;5:320-9.

53. Osenbach RK, Menezes AH. Pediatric spinal cord and vertebral column injury. Neurosurgery 1992;30:385-90.

54. Hamilton MG, Myles ST. Pediatric spinal injury: review of 174 hospital admissions. J Neurosurg 1992;77:7004.

55. Augutis M, Levi R. Pediatric spinal cord injury in Sweden: incidence, etiology and outcome. Spinal Cord 2003;41:328-36.

56. Sayama C, Chen T, Trost G, Jea A. A review of pediatric lumbar spine trauma. Neurosurg Focus 2014;37:E6.

57. Leucht P, Fischer K, Muhr G, Mueller EJ. Epidemiology of traumatic spine fractures. Injury 2009;40:166-72.

58. Nau C, Jakob H, Lehnert M, et al. Epidemiology and Management of Injuries to the Spinal Cord and Column in Pediatric Multiple-Trauma Patients. Eur J Trauma 2010;36:339-45.

59. Álvarez-Pérez MJ, López-Llano ML. Lesion medular traumatica en la infancia y adolescencia en Asturias. Rev Neurol 2015;60:401-7.

60. Leonard JR, Jaffe DM, Kuppermann N, et al. Cervical spine injury patterns in children. Pediatrics 2014;133:88.

61. Mortazavi M, Gore PA, Chang S, et al. Pediatric cervical spine injuries: a comprehensive review. Childs Nerv Syst 2011;27:705-17.

62. Murphy RF, Davidson AR, Kelly DM, et al. Subaxial cervical spine injuries in children and adolescents. J Pediatr Orthop 2015;35:136-9.

63. Patel JC, Tepas JJ, Mollitt DL, Pieper P. Pediatric cervical spine injuries: defining the disease. J Pediatr Surg 2001;36:373-6.

64. Schottler J, Vogel LC, Sturm P. Spinal cord injuries in young children: a review of children injured at 5 years of age and younger. Dev Med Child Neurol 2012;54:1138-43.

65. Dogan S, Safavi-Abbasi S, Theodore N, et al. Thoracolumbar and sacral spinal injuries in children and adolescents: a review of 89 cases. J Neurosurg 2007;106:426-33.

66. Tiling $\mathrm{T}$, Werbein $\mathrm{H}$, Stuhler $\mathrm{T}$, Stankovic P. Experimentelle Untersuchungen zur Biomechanik der kindlichen Wirbelkörperfraktur. Chir Forum Exp Klin Forsch 1980:1-5.

67. Kathrein A, Huber B, Waldegger M, et al. Management of injuries of the tho- racic and lumbar vertebrae in children. Orthopade 1999;28:441-50.

68. Jarvers JS, Spiegl U, von der Hoh NJ, et al. Injuries of the thoracolumbar spine in children. Orthopade 2016;45:472-83.

69. Suttor S, Gray R, Bridge C, Cree A. Operative treatment of chance injuries in the paediatric population. Eur Spine J 2013;22:510-4.

70. Arbes S, Platzer P, Vecsei V. Fractures of the thoracolumbar spine in childhood and adolescence. Unfallchirurg. 2012;115:1070-5.

71. Erfani MA, Pourabbas B, Nouraie H, et al. Results of fusion and instrumentation of thoracic and lumbar vertebral fractures in children: a prospective tenyear study. Musculoskelet Surg 2014;98:107-14.

72. Williams BJ, Smith JS, Saulle D, et al. Complications associated with surgical treatment of traumatic spinal fractures: a review of the scoliosis research society morbidity and mortality database. World Neurosurg 2014;81:818-24.

73. Firth GB, Kingwell SP, Moroz PJ. Pediatric noncontiguous spinal injuries: the 15-year experience at a level 1 trauma center. Spine 2012;37:608.

74. Mortazavi MM, Dogan S, Civelek E, et al. Pediatric multilevel spine injuries: an institutional experience. Childs Nerv Syst 2011;27:1095-100.

75. Mahan ST, Mooney DP, Karlin LI, Hresko MT. Multiple level injuries in pediatric spinal trauma. J Trauma 2009;67:537-42.

76. Henrys P, Lyne ED, Lifton C, Salciccioli G. Clinical review of cervical spine injuries in children. Clin Orthop Relat Res 1977:172-6.

77. Schwarz N, Ohner T, Schwarz AF, et al. Verletzungen der Halswirbelsäule bei Kindern und Jugendlichen. Unfallchirurg 1993;96:235-41.

78. Aufdermaur M. Spinal injuries in juveniles. Necropsy findings in twelve cases. J Bone Joint Surg Br 1974; 56B:513-9. 